\title{
Short Peptides as Inhibitors of Amyloid Aggregation
}

\author{
Bradley Neddenriep, Anastasia Calciano, Daniel Conti, Erin Sauve, Marissa Paterson, \\ Edward Bruno and David A. Moffet*
}

Department of Chemistry and Biochemistry Loyola Marymount University 1 LMU Drive Los Angeles, CA 90045, USA

\begin{abstract}
The misfolding and aggregation of proteins into amyloid has been linked to a variety of age-related diseases. Aggregation of proteins, such as A $\beta$ in Alzheimer's disease and Islet Amyloid Polypeptide (IAPP, amylin) in type 2 diabetes, appears to lead to the formation of toxic assemblies. These assemblies range in size from small oligomers (2-8 proteins) to large fibrils (thousands of proteins). It remains unclear how these amyloidogenic proteins misfold and form toxic species, but growing evidence suggests that inhibiting the aggregation of these proteins could slow, if not prevent altogether, the progression of these diseases. We describe the use of small peptides ( $<43$ amino acids) as inhibitors of amyloid-based aggregation. These peptides, often short complementary segments of the amyloid proteins, can be useful (i) for identifying the aggregation-prone regions of the amyloid proteins (ii) as models for drug discovery and (iii) as potential therapeutic agents themselves.
\end{abstract}

Keywords: Amyloid Inhibition, Peptide Libraries, ABeta, Amylin, IAPP.

\section{INTRODUCTION}

Many proteins are known to adopt unwanted, misfolded structures that can be linked to a variety of age-related diseases [1-3]. Proteins such as Islet Amyloid Polypeptide (IAPP, amylin) in type 2 diabetes and A 42 in Alzheimer's disease are known to misfold and aggregate into toxic oligomers and fibers. In these amyloid diseases, proteins misfold and self-assemble into a variety of structures. It remains unknown if these misfolded proteins are the cause of their respective diseases or a side-effect. However, evidence is accumulating to suggest that the aggregation of amyloid proteins plays an important role in the development and progression of these diseases.

The amyloid diseases represent a serious threat to our overall global health. Within the United States, the economic and social costs associated with Alzheimer's disease and type 2 diabetes have been well documented over the past decade. The Alzheimer's Association estimates that 5.1 million Americans are currently afflicted with Alzheimer's disease [4]. Likewise, the American Diabetes Association estimates that 23.6 million children and adults in the United States have diabetes [5]. Because the prevalence of these diseases increases with age, the number of people afflicted with Alzheimer's disease and type 2 diabetes will increase as the population ages. If no treatments are found to slow these diseases, it is estimated that 11 to 16 million Americans will be afflicted with Alzheimer's disease by 2050 [4] and as many as 100 million Americans could have diabetes by that time [6]. The economic costs of just these two amyloidogenic diseases is estimated to be more than $\$ 148$ billion annually for Alzheimer's disease and \$174 billion for type 2 diabetes.

*Address correspondence to this author at the Department of Chemistry and Biochemistry Loyola Marymount University 1 LMU Drive Los Angeles, CA 90045, USA; Tel: 310-338-4400; Fax: 001-310-338-2905;

E-mail: dmoffet@1mu.edu
While the amyloidogenic proteins differ in many ways (length, organismal localization, amino acid compositions), they all form well-ordered fibrils and appear to be toxic to living cells [7-14]. These similarities are not solely shared by naturally occurring proteins, but have been identified in designed proteins expressed in mammalian cells [15]. These results indicate that the formation of protein aggregates, whether they are small oligomers or large fibrils, plays a central role in cell toxicity and disease pathology. These studies suggest that the mechanism of this cellular toxicity is likely conserved from one amyloid protein to the next. These results raise the hope that if a strategy is uncovered to prevent amyloid formation for one disease, the same strategy may lead to therapies for many, if not all, of the remaining amyloid diseases.

Many strategies are currently being assessed for preventing the formation of amyloid and toxic oligomers. Some strategies rely on preventing the production of the amyloid protein in the first place (for instance, inhibiting $\gamma$-secretase activity in $A \beta$ production). Some strategies rely on removing the amyloid protein after it has been produced (such as using antibodies to remove $A \beta$ ). Both of these strategies hold great potential for slowing and/or preventing the onset of amyloidbased diseases. However, it remains to be determined if the amyloid proteins themselves serve a useful purpose to the organism. There may be a benefit to having the protein that has not yet been determined. With this in mind, there have been some recent successes made in slowing the rate of aggregation of amyloid proteins without having to remove the protein entirely. Several classes of small molecules have been identified as showing some activity toward inhibiting the formation of amyloid. [16-27]. While small-molecule aggregation inhibitors have been reported, none have been developed into a clinically useful therapeutic. 
Since 2002, we have seen a considerable increase in the number of reports identifying short peptides as inhibitors of amyloid formation. While none of these peptides have been developed into a therapeutic, the potential does exist. Unlike small-molecule inhibitors of amyloid aggregation, short peptides can yield information regarding the amyloid aggregates themselves. Many of the peptide inhibitors are truncated versions of the full-length amyloid proteins. By identifying the sequence regions that inhibit aggregation, we can infer that those are the regions responsible for driving amyloid aggregation. In this review, we will focus on the short peptide sequences comprised of naturally occurring amino acids that have been identified for their ability to inhibit the aggregation of the amyloidogenic proteins A $\beta$ (Alzheimer's disease) and IAPP (type 2 diabetes).

\section{PEPTIDE INHIBITION OF ABETA AGGREGATION}

Peptides showing an ability to inhibit the aggregation of $A \beta$ can be organized into two major groups; rationally designed peptides (which are typically similar in sequence to that of wild-type $A \beta$ ) and randomly generated peptides (those which are identified from peptide libraries that may, or may not, show sequence similarity to wild-type $A \beta$ ). The advances made in molecular biology and biotechnology in the past decade have made it possible to construct and screen large peptide libraries to identify those sequences that interact with $A \beta$. These library-screening experiments, which were either impossible or impractical just a few years ago, have successfully identified several amyloid inhibitors.

\section{Rationally Designed Peptide Inhibitors of A $\beta$ Aggregation}

The earliest attempts to identify $\mathrm{A} \beta$ aggregation inhibitors came from the sequence of $A \beta$ itself (Table 1). Many of the first peptide inhibitors were designed to target the aggregation-prone hydrophobic core region of $\mathrm{A} \beta$. This region
(LVFFA) is considered by many to be the primary aggregation-prone site of $A \beta$ and is often termed the self-recognition site [28-30]. Many rationally designed peptides retain the LVFFA sequence, with the hope that the inhibitor peptide will selectively bind to the analogous sequence of natural A $\beta 42$ [28, 31-34]. What often differs among these peptides are the $\mathrm{N}$ and $\mathrm{C}$-terminal amino acids surrounding the LVFFA core. These surrounding residues are thought to act as aggregation blockers (termed $\beta$-sheet breakers), preventing additional amyloid peptides from adhering to the $A \beta$ peptide complex [35]. Many of these LVFFA peptides, and their later-generation variants, have been shown to inhibit $\mathrm{A} \beta$ aggregation at stoichiometric concentrations and rescue living cells from the toxic effects of $A \beta 42$. For example, Garno and coworkers recently synthesized and studied 15 different variants having KLVFF as the core sequence (additional residues were added to the $\mathrm{N}$-terminus and/or the $\mathrm{C}$ terminus of this core sequence) [31]. From Thioflavin $\mathrm{T}$ and transmission electron microscopy experiments, nearly all of these peptides possessed some ability to inhibit aggregation at a 1:1 molar ratio $(40 \mu \mathrm{M}$ peptide to $40 \mu \mathrm{M}$ A $\beta 40)$. Several peptides inhibited aggregation by approximately $80 \%$ compared to samples lacking the inhibitory peptides. Atomic force microscopy was used to identify the aggregation products of $A \beta 40$ alone, the peptides alone and $A \beta 40$ in the presence of the peptide inhibitors. Several peptides were found to self-aggregate into spherical assemblies, yet still showed inhibitory capacity. They found that placing positively charged residues at the N-terminal end of the KLVFF sequence were less likely to inhibit than if positive amino acids were placed at the $\mathrm{C}$-terminal end. The authors also concluded that the peptides with the highest affinity to $A \beta 40$ showed the greatest ability to inhibit amyloid-based aggregation. These results seem to be typical of the KLVFF core peptide inhibitors. These peptides demonstrate the potential of rationally designed peptide inhibitors as amyloid blocking agents.

Table 1. Peptide Inhibitors of Aß42

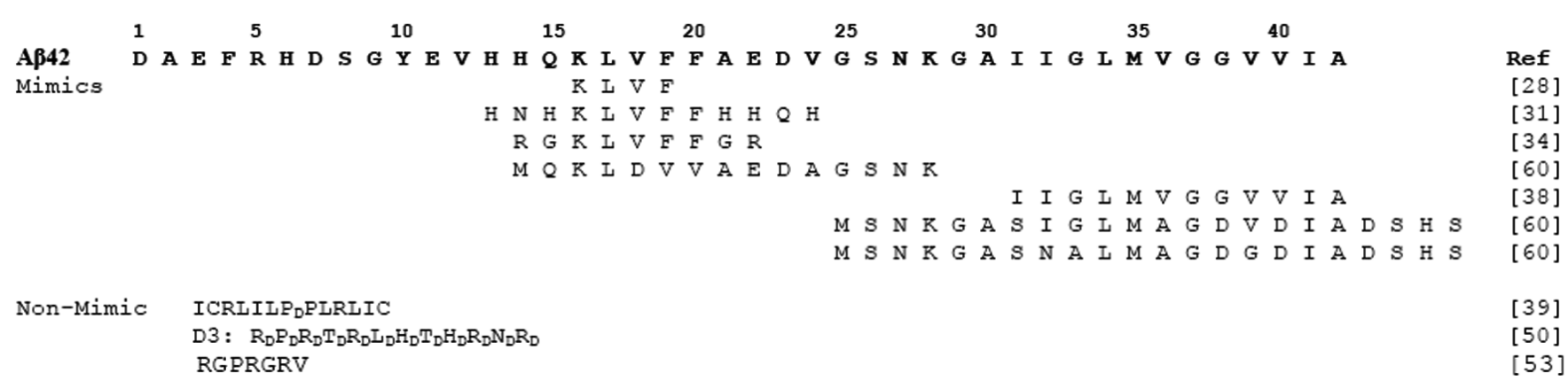

Table 2. Peptide Inhibitors of IAPP

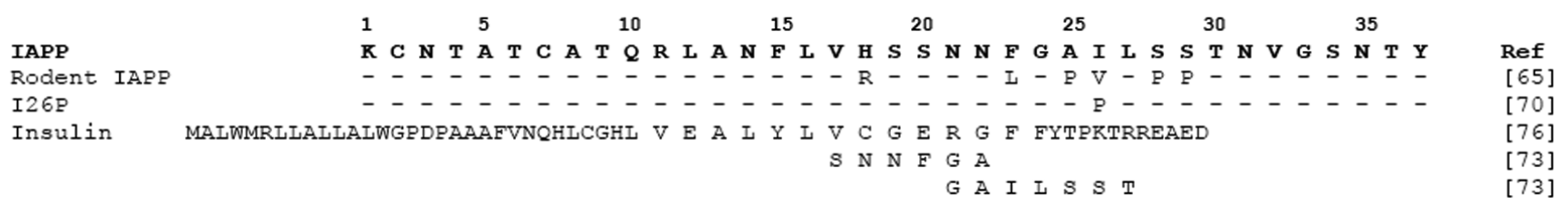


The hydrophobic core of $A \beta 42$ is not the only region targeted for inhibition of aggregation. A $\beta 42$ aggregation has been inhibited using C-terminal fragment (CTF) sequences of various lengths [36-38]. The best of these inhibitors spanned the final 13, 11 and 4 amino acids of $\mathrm{A} \beta 42$ [38], indicating that the length of the inhibitor peptide did not necessarily correlate with inhibitory propensity. Instead, the best correlation between CTF and their physical properties appeared to rely on the ability of the CTF to form a coil-turn conformation [38]. This conformation seems to appear in other inhibitory models, such as the peptide hairpin inhibitor of Teplow and coworkers [39]. While this peptide does contain one D-amino acid (D-Proline), the polypeptide is believed to form a hairpin turn held together by a disulfide bridge.

The rationally designed peptides have proven to be a strong class of inhibitory agents for $A \beta 42$. These peptides continue to be modified with the ultimate goal to increase their ability to inhibit amyloid aggregation. Many of these peptides have been found to protect living cells from toxic amyloid aggregates. Perhaps future iterations of these peptides will show even greater ability to protect cellular viability.

\section{Peptide Inhibitors of A $\beta$ Aggregation Selected from Combinatorial Libraries}

Advances in molecular biology, coupled with the decreased cost of DNA synthesis, have led to a greater ability to generate high-quality gene/protein libraries [40]. Libraries that once took months to construct, can now be done in a matter of weeks. While the ability to construct gene libraries has greatly evolved over the past decade, the ability to select for those variants that show a desirable activity has not. There are very few techniques in the literature that describe screens to select for peptides that inhibit amyloid aggregation and protect living cells from toxic protein aggregates. Despite this paucity of screening techniques, those screens that have been utilized have proven to be successful at identifying multiple amyloid-inhibiting peptides. We will discuss each of these screening techniques and the inhibitory peptides they have identified.

\section{Peptides Identified Using Phage-Display}

Phage display has proven to be an excellent method for screening large libraries of peptides to select for those that bind to an epitope of interest [41]. Many of the libraries screened by phage display have targeted large peptides/proteins. These libraries of larger peptides have generated sequences that inhibit $A \beta$ aggregation, but may prove difficult to convert into a therapeutically useful drug. For example, several papers have been published recently that describe antibody-based, affibody, and other scaffold-based proteins selected by phage display [42-52]. Many of these selected proteins have been shown to inhibit aggregation, but their therapeutic potential remains untested.

Kamijo and coworkers recently screened a randomized heptapeptide library against $A \beta 42$ [53]. Their goal was to identify peptides that could bind $A \beta 42$, but did not necessarily possess sequence similarities to A $\beta 42$. They identified several peptides, rich in arginines, that showed in vitro ability to inhibit A $\beta 42$ aggregation. Size-exclusion chromatography and SDS-PAGE gel-shift assays indicated that several of these selected peptides kept $A \beta 42$ from forming soluble oligomers [53]. Additional experiments will need to be performed to assess how these peptides inhibit aggregation. Of specific interest is why arginine-rich sequences were highly selected in this screen.

Not all peptides identified with phage display have been found to inhibit aggregation. Kiessling and coworkers identified several peptides that could bind to different aggregation states of $A \beta 40$ [54]. While several peptides were identified that could bind to $A \beta 40$, none slowed the rate of aggregation, and many increased aggregation. Therapeutically, this increase in aggregation could be beneficial if, in fact, aggre-

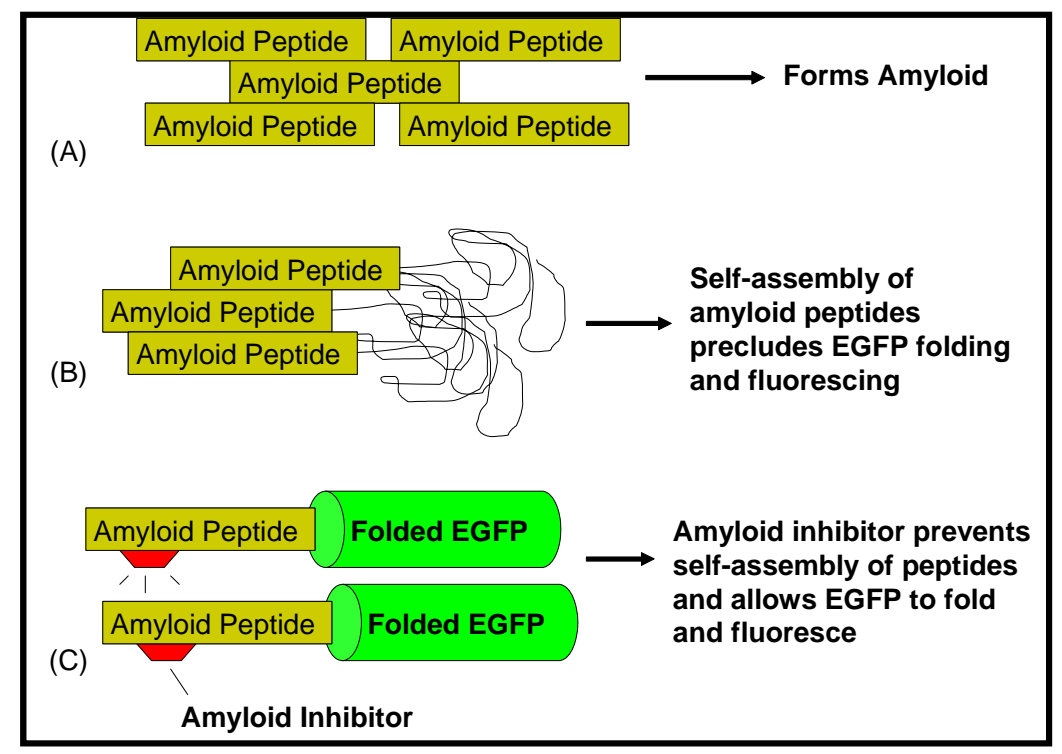

Fig. (1). (A) Amyloidogenic peptides, such as A $\beta 42$ and IAPP self-assemble, ultimately leading to the formation of amyloid. (B) When linked to an amyloid peptide, EGFP does not fold or fluoresce. The aggregation of the amyloid peptides prevents proper folding and fluorescence of EGFP. (C) Inhibitors that prevent the self-assembly of the amyloid peptides allow the EGFP to fold and fluoresce. 
Fig. (2). Amino Acid Sequences of A $\beta 42$ and Library 1 and Library 2 Peptides. The amino acid sequence for A $\beta 42$ is shown. Library 1 was constructed to have mixtures of amino acids in the bold-faced positions. Degenerate gene construction: Codon ANT encodes for an equal mixture of I, T, N and S. Codon GNT encodes for an equal mixture of V, A, D and G. Codon NTN encodes for a mixture of F, L, I, M and V.

Table 3. Oligos Used for the Construction of Gene Libraries 1 and 2

\begin{tabular}{|l|l|}
\hline Library 1 Forward & $\begin{array}{l}\text { 5'-CTAGCTGT CAT ATG TCT AAC AAA GGC GCG ANT ANT GNT CTG ATG GNT GNT GNT GNT GNT ATT GCG GAT } \\
\text { AGT CAT AGT TAA-3' }\end{array}$ \\
\hline Library 2 Forward & $\begin{array}{l}\text { 5'-CTAGCTGT CAT ATG CAG AAA CTG GNT DTN DTN GCG GAA GNT GNT GGC TCT AAC AAA TAA ATT GCG } \\
\text { GAT AGT CAT AGT TAA-3' }\end{array}$ \\
\hline Reverse & $\begin{array}{l}\text { 5'-CGATAGGAC GAATTC CAG TGG TAG CTT GTG TGC CAA CAG TAG TTA ACG GTA GAA CCG TTA ACT ATG } \\
\text { ACT ATC CGC AAT -3' }\end{array}$ \\
\hline
\end{tabular}

Degenerate codons are underlined. Complementary regions are colored blue. All oligos are written from 5' -3'. N: equal mixture of A, T, G and C. D: Equal mixture of A, G and T.

gated $\mathrm{A} \beta$ is less toxic than small oligomers. These aggregation-enhancing peptides may function to help sequester A $\beta 40$ into less toxic fibrils rather than the more toxic soluble oligomers.

\section{Peptides Identified Using AB42-EGFP}

Hecht and coworkers described the use of a GFP-based screen to assess the in vivo aggregation propensity of $\mathrm{A} \beta 42$ in $E$. coli cells $[29,55]$. This screen has been used to assess the aggregation potential of $\mathrm{A} \beta$ mutants [55-57] as well as to screen for small molecules that can inhibit aggregation [58]. We recently used this screen, replacing GFP with enhanced GFP (EGFP) to select for mutants of IAPP that resisted aggregation [59]. In this screen, the amyloid protein (such as A $\beta 42$ or IAPP) is genetically fused to the reporter protein EGFP. When expressed in E. coli, the Amyloid-EGFP fusion proteins produce virtually no green color or fluorescence due to the propensity of the amyloid proteins to aggregate (Fig. 1). However, when the amyloid proteins are prevented from aggregating (either by mutagenesis or in the presence of an aggregation inhibitor), the fused EGFP folds and fluoresces brightly.

We have recently used this screen to select peptides from different combinatorially randomized libraries for their ability to inhibit $A \beta 42$ aggregation [60]. Combinatorially diverse library peptides were co-expressed in E. coli with the A $\beta 42-$ EGFP fusion protein. Peptides that prevented the aggregation of the A $\beta 42$ allowed EGFP to fold and fluoresce. Individual $E$. coli colonies expressing both a library peptide and amyloid-EGFP were screened to select for those colonies that showed the greatest fluoresce. Using this screen, we identi- fied three short peptides capable of inhibiting A $\beta 42$ aggregation [60]. We believe this screen can be used to select for increasingly potent inhibitors of A $\beta 42$ by improving the selection conditions and the combinatorial library design.

Gene libraries can be easily constructed using a variety of techniques. Gene libraries can be designed to encode for short peptides targeted to anneal to, and disrupt aggregation of, the amyloidogenic A $\beta 42$ peptide. For example, Fig (2) shows two peptide libraries targeted to mimic each of the two hydrophobic regions of $A \beta 42$. Both gene libraries were constructed using synthetic single-stranded oligos* (Table 3) and pieced together using oligo overlap and extension (Fig. 3). Gene variability was introduced to the gene libraries by using degenerate codons encoding for combinatorial mixtures of amino acids (Table $\mathbf{3}$ ).

Both peptide libraries were designed to mimic the hydrophobic patches of $A \beta 42$, with the intention of producing peptides that could anneal to the monomeric form of $A \beta 42$. Also designed into the peptide libraries are strongly polar and charged aspartic acid residues. These acidic residues are intended to incorporate a strongly charged "bump" on the library peptides that prevents the aggregation of additional A $\beta 42$ proteins to an A $\beta 42$-library peptide complex. The library peptides are designed to act as two-sided patches; one

'Library 1: 5'-CTAGCTGT CAT ATG TCT AAC AAA GGC GCG ANT ANT GNT CTG ATG GNT GNT GNT GNT GNT ATT GCG GAT AGT CAT AGT TAA-3', Library 2: 5'-CTAGCTGT CAT ATG CAG AAA CTG GNT DTN DTN GCG GAA GNT GNT GGC TCT AAC AAA TAA ATT GCG GAT AGT CAT AGT TAA-3', Reverse sequence for both libraries: 5'- CGATAGGAC GAATTC CAG TGG TAG CTT GTG TGC CAA CAG TAG TTA ACG GTA GAA CCG TTA ACT ATG ACT ATC CGC AAT -3'. 
side being sticky and annealing to monomeric $A \beta 42$, and the other side presenting a repulsive residue (or residues) that prevent additional $A \beta 42$ peptides from annealing.

The gene library is cloned into one plasmid and cotransformed with the amyloid-EGFP plasmid into a suitable $E$. coli expression host (Fig. 4). The resultant colonies are transferred to plates that can induce protein expression. With this system, thousands of transformed colonies can be screened to identify those few that show elevated levels of EGFP fluorescence.

\section{PEPTIDE INHIBITORS OF IAPP AGGREGATION}

In type II diabetes the amyloid-forming peptide is islet amyloid polypeptide (IAPP, amylin). This 37 amino acid polypeptide misfolds and forms toxic aggregates within the pancreas. This misfolding into toxic aggregates, such as small soluble oligomers or large fibers, is believed to contribute to the loss of pancreatic $\beta$-cells. A great debate continues within the scientific community to identify the toxic form (or forms) of IAPP. While the exact role of IAPP in type II diabetes is unclear, it is known that IAPP is found as extracellular deposits of amyloid in approximately $90 \%$ of patients afflicted with type II diabetes [61-63]. This peptide is highly amyloidogenic, finding any substance to inhibit its aggregation could be a potent weapon in the fight against type 2 diabetes.

It is well established that rodent IAPP (rIAPP) is nonamyloidogenic and nontoxic. It is also established that rats and mice are not known to develop type II diabetes [64], strengthening the argument that inhibiting IAPP aggregation could help to prevent type 2 diabetes. Rodent IAPP, which differs from human IAPP by six amino acids, has been demonstrated to be capable of inhibiting human IAPP aggregation [65].

Five of the substitutions known to convert amyloidogenic human IAPP into non-amyloidogenic rodent IAPP occur in the 20-29 region of the peptide (Table 2). Because of these substitutions the 20-29 region has long been described as the amyloidogenic region of IAPP [32, 66, 67]. Recent studies have indicated that several mutations outside of the 20-29 region can hinder fibrillogenesis, and are likely important for aggregation [59, 68-74]. Several short peptides targeting this aggregation-prone region have been identified [73]. Additionally, a single mutation in the middle of this aggregation region, I26P, has been shown to act as a potent inhibitor of IAPP aggregation [70].

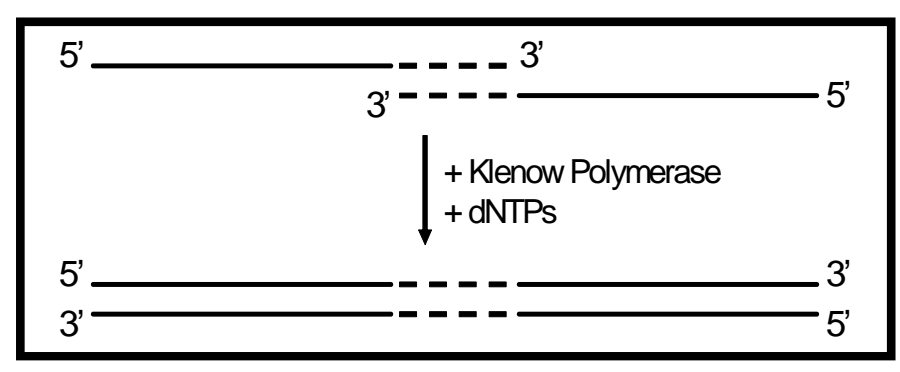

Fig. (3). Oligo overlap and extension: Single-stranded DNA oligos were designed having complementary 3' overhang regions (dashed lines). When mixed, the complementary regions anneal and act as templates for Klenow Fragment catalyzed DNA synthesis. Nucleotides not involved in annealing (solid lines) can be explicitly designed base by base or combinatorially varied.

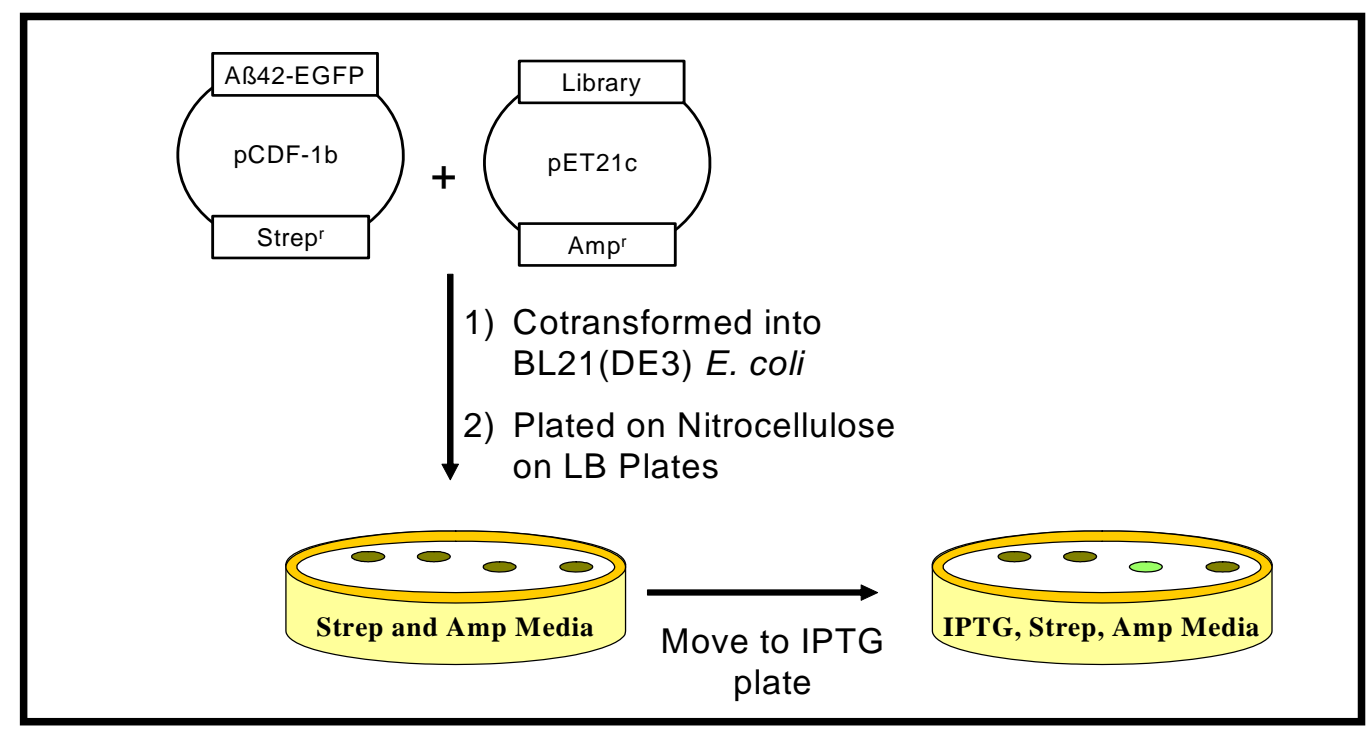

Fig. (4). Construction and selection of peptide libraries. Cotransformed cells were plated on nitrocellulose absorbed on LB plates containing Ampicillin and Streptomycin. After incubation, resulting colonies are transferred to LB plates containing IPTG. Green-colored colonies are selected and analyzed. 
Insulin is an additional peptide that is known to inhibit IAPP aggregation [75]. Insulin is co-secreted with IAPP from pancreatic B-cells. While the exact role these two peptides play in the development of type 2 diabetes remains to be determined, it is not surprising that this metabolismdriving hormone is important in preventing IAPP aggregation. Raleigh and coworkers were able to determine the crystal structure of IAPP fused to maltose binding protein [76]. Based on the structure of IAPP in this fusion protein, they were able to model the possible binding interaction between IAPP and the B-chain of insulin, showing the importance of IAPP Phe15 in this aggregation (Table 2 shows the sequence of insulin as well as the residues of insulin suggested as interacting with IAPP).

In one of the few articles describing short peptide inhibitors of IAPP aggregation, Fraser and coworkers tested a series of hexapeptides, each overlapping with a segment of IAPP [73]. When co-incubated with IAPP, several of the peptides, such as GAILSST appeared to decrease the density of fiber formation. More importantly, one peptide SNNFGA (Table 2) had the ability to rescue cultured cells from IAPP toxicity.

\section{OUTLOOK}

Over the past decade, we have witnessed a great increase in the number of articles describing short peptides as inhibitors of amyloid aggregation. Advances in molecular biology (which allows for the inexpensive synthesis of DNA libraries) and peptide synthesis (which have lowered the costs of chemically synthesizing peptides) have made it possible to both identify and synthesize specific peptides capable of inhibiting aggregation. While it remains to be seen whether short peptides can be used as therapeutic agents in preventing the amyloid diseases, these short peptide inhibitors can aid in identifying the aggregation-prone regions of the amyloid proteins. These short peptide inhibitors can also be useful in identifying the important characteristics of potential therapeutic agents in amyloid inhibition. Perhaps future iterations of peptides will be identified that can protect cells from amyloid aggregates as well as resist our body's natural protein degradation machinery.

\section{CONFLICT OF INTEREST}

None declared.

\section{ACKNOWLEDGEMENTS}

We thank Luiza A. Nogaj for critical reading of this manuscript. Funding for this work was from the National Institutes of Health (1R15AG032582).

\section{ABBREVIATIONS}

$$
\begin{array}{lll}
\text { IAPP } & = & \text { Islet amyloid polypeptide } \\
\mathrm{A} \beta & = & \text { Amyloid } \beta \text {-protein } \\
\mathrm{EGFP} & = & \text { Enhanced green fluorescent protein }
\end{array}
$$

\section{REFERENCES}

[1] Bucciantini M, Giannoni E, Chiti F et al. Inherent toxicity of aggregates implies a common mechanism for protein misfolding diseases. Nature 2002; 416: 507-11.
[2] Chiti F, Dobson CM. Protein misfolding, functional amyloid, and human disease. Annu Rev Biochem 2006; 75: 333-66.

[3] Murphy RM, Kendrick BS. Protein misfolding and aggregation. Biotech Progress 2007; 23: 548-52.

[4] Alzheimer's Disease Facts and Figures. Alzheimer's Association 2007; Available from: http://www.alz.org/.

[5] Type 2 Diabetes Facts and Figures. American Diabetes Association 2007; Available from: http://www.diabetes.org

[6] CDC Revise Estimates, Predicts 100 Million Americans Could be Diabetic by 2050. Centers for Disease Control and Prevention 2010.

[7] Ritzel RA, Meier JJ, Lin CY, Veldhuis JD, Butler PC. Human islet amyloid polypeptide oligomers disrupt cell coupling, induce apoptosis, and impair insulin secretion in isolated human islets. Diabetes 2007; 56: 65-71.

[8] Yan LM, Velkova A, Tatarek-Nossol M, Andreetto E, Kapurniotu A. LAPP mimic blocks A beta cytotoxic self-assembly: Crosssuppression of amyloid toxicity of A beta and IAPP suggests a molecular link between Alzheimer's disease and type II diabetes. Angew Chem-Int Ed 2007; 46: 1246-52.

[9] Kapurniotu A, Schmauder A, Tenidis K. Structure-based design and study of non-amyloidogenic, double N-methylated IAPP amyloid core sequences as inhibitors of IAPP amyloid formation and cytotoxicity. J Mol Biol 2002; 315: 39-50.

[10] Kayed R, Head E, Thompson JL, et al. Common structure of soluble amyloid oligomers implies common mechanism of pathogenesis. Science 2003; 300: 486-89.

[11] Fezoui Y, Hartley DM, Walsh DM, Selkoe DJ, Osterhout JJ, Teplow DB. A de novo designed helix-turn-helix peptide forms nontoxic amyloid fibrils. Nat Struct Biol 2000; 7: 1095-9.

[12] Wakabayashi M, Matsuzaki K. Ganglioside-induced amyloid formation by human islet amyloid polypeptide in lipid rafts. FEBS Lett 2009; 583: 2854-8.

[13] Last NB, Rhoades E, Miranker AD. Islet amyloid polypeptide demonstrates a persistent capacity to disrupt membrane integrity. Proc Natl Acad Sci USA 2011; 108: 9460-5.

[14] Bucciantini M, Calloni G, Chiti F, et al. Prefibrillar amyloid protein aggregates share common features of cytotoxicity. J Biol Chem 2004; 279: 31374-82.

[15] Olzscha H, Schermann SM, Woerner AC, et al. Amyloid-like aggregates sequester numerous metastable proteins with essential cellular functions. Cell 2011; 144: 67-78.

[16] Ritchie CW, Bush AI, Mackinnon A et al. Metal-protein attenuation with iodochlorhydroxyquin (clioquinol) targeting Abeta amyloid deposition and toxicity in Alzheimer disease: a pilot phase 2 clinical trial. Arch Neurol 2003; 60: 1685-91.

[17] Ritchie CW, Bush AI, Masters CL. Metal-protein attenuating compounds and Alzheimer's disease. Expert Opin Investig Drugs 2004; 13: $1585-92$.

[18] Wood SJ, MacKenzie L, Maleeff B, Hurle MR, Wetzel R. Selective inhibition of Abeta fibril formation. J Biol Chem 1996; 271: 4086-92.

[19] Lashuel HA, Hartley DM, Balakhaneh D, Aggarwal A, Teichberg S, Callaway DJ. New class of inhibitors of amyloid-beta fibril formation. Implications for the mechanism of pathogenesis in Alzheimer's disease. J Biol Chem 2002; 277: 42881-90.

[20] Talaga P. Beta-amyloid aggregation inhibitors for the treatment of Alzheimer's disease: dream or reality? Mini Rev Med Chem 2001; 1: $175-86$.

[21] Cohen T, Frydman-Marom A, Rechter M, Gazit E. Inhibition of amyloid fibril formation and cytotoxicity by hydroxyindole derivatives. Biochemistry 2006; 45: 4727-35.

[22] Porat Y, Abramowitz A, Gazit E. Inhibition of amyloid fibril formation by polyphenols: structural similarity and aromatic interactions as a common inhibition mechanism. Chem Biol Drug Des 2006; 67: 27-37.

[23] Porat Y, Mazor Y, Efrat S, Gazit E. Inhibition of islet amyloid polypeptide fibril formation: a potential role for heteroaromatic interactions. Biochemistry 2004; 43: 14454-62.

[24] Saengkhae C, Salerno M, Ades D et al. Ability of carbazole salts, inhibitors of Alzheimer beta-amyloid fibril formation, to cross cellular membranes. Eur J Pharm 2007; 559: 124-31.

[25] Riviere C, Richard T, Quentin L, Krisa S, Merillon JM, Monti JP. Inhibitory activity of stilbenes on Alzheimer's beta-amyloid fibrils in vitro. Bioorg Med Chem 2007; 15: 1160-7. 
[26] Hull RL, Zraika S, Udaya-Sankar J, Kisilevsky R, Szarek WA, Kahn SE. Inhibition of islet amyloid formation in vitro by a small molecule inhibitor that reduces heparan sulfate proteoglycan (HSPG) synthesis. Diabetes 2006; 55: A372.

[27] Hamaguchi T, Ono K, Yamada M. Anti-amyloidogenic therapies: strategies for prevention and treatment of Alzheimer's disease. Cell Mol Life Sci 2006; 63: 1538-52.

[28] Estrada LD, Soto C. Inhibition of protein misfolding and aggregation by small rationally-designed peptides. Curr Pharma Des 2006; 12: 2557-67.

[29] Wurth C, Kim W, Hecht MH. Combinatorial approaches to probe the sequence determinants of protein aggregation and amyloidogenicity. Protein Pept Lett 2006; 13: 279-86.

[30] Esler WP, Stimson ER, Ghilardi JR et al. Point substitution in the central hydrophobic cluster of a human beta-amyloid congener disrupts peptide folding and abolishes plaque competence. Biochemistry $1996 ; 35: 13914-21$.

[31] Bett CK, Serem WK, Fontenot KR, Hammer RP, Garno JC. Effects of peptides derived from terminal modifications of the A beta central hydrophobic core on A beta fibrillization. ACS Chem Neurosci 2010; 1: 661-78.

[32] Gazit E. Mechanisms of amyloid fibril self-assembly and inhibition. FEBS J 2005; 272: 5971-8.

[33] Orner BP, Liu L, Murphy RM, Kiessling LL. Phage display affords peptides that modulate beta-amyloid aggregation. J Am Chem Soc 2006; 128: 11882-9.

[34] Austen BM, Paleologou KE, Ali SAE, Qureshi MM, Allsop D, ElAgnaf OMA. Designing peptide inhibitors for oligomerization and toxicity of Alzheimer's beta-amyloid peptide. Biochemistry 2008; 47: 1984-92.

[35] Poduslo JF, Curran GL, Kumar A, Frangione B, Soto C. Beta-sheet breaker peptide inhibitor of Alzheimer's amyloidogenesis with increased blood-brain barrier permeability and resistance to proteolytic degradation in plasma. J Neurobiol 1999; 39: 371-82.

[36] Li HY, Monien BH, Lomakin A, et al. Mechanistic investigation of the inhibition of A beta 42 assembly and neurotoxicity by A beta 42 C-terminal fragments. Biochemistry 2010; 49: 6358-64.

[37] Monien BH, Fradinger EA, Spring SM, Bernstein SL, Bowers MT, Bitan G. A novel approach to Alzheimer's disease therapy: Inhibition of A beta 42 oligomerization by C-terminal A beta 42 fragments. J Pept Sci 2006; 12: 147-7.

[38] Li HY, Monien BH, Fradinger EA, Urbanc B, Bitan G. Biophysical characterization of A beta $42 \mathrm{C}$-terminal fragments: inhibitors of A beta 42 neurotoxicity. Biochemistry 2010; 49: 1259-67.

[39] Yamin G, Ruchala P, Teplow DB. A peptide hairpin inhibitor of amyloid beta-protein oligomerization and fibrillogenesis. Biochemistry 2009; 48: 11329-31.

[40] Moffet DA, Hecht MH. De novo proteins from combinatorial libraries. Chem Rev 2001; 101: 3191-203.

[41] Smith GP, Petrenko VA. Phage display. Chem Rev 1997; 97: 391410.

[42] Habicht G, Haupt C, Friedrich RP, et al. Directed selection of a conformational antibody domain that prevents mature amyloid fibril formation by stabilizing A beta protofibrils. Proc Natl Acad Sci USA 2007; 104: 19232-7.

[43] O'Nuallain B, Allen A, Ataman D, Weiss DT, Solomon A, Wall JS. Phage display and peptide mapping of an immunoglobulin light chain fibril-related conformational epitopet. Biochemistry 2007; 46: 13049-58.

[44] Frenkel D, Solomon B, Benhar I. Modulation of Alzheimer's betaamyloid neurotoxicity by site-directed single-chain antibody. J Neuroimmunol 2000; 106: 23-31

[45] Manoutcharian K, Acero G, Munguia ME, et al. Amyloid-beta peptide-specific single chain $\mathrm{Fv}$ antibodies isolated from an immune phage display library. J Neuroimmunol 2003; 145: 12-17.

[46] Lindgren J, Wahlstrom A, Danielsson J, et al. N-terminal engineering of amyloid-beta-binding Affibody molecules yields improved chemical synthesis and higher binding affinity. Protein Sci 2010; 19: 2319-29.

[47] Hoyer W, Gronwall C, Jonsson A, Stahl S, Hard T. Stabilization of a beta-hairpin in monomeric Alzheimer's amyloid-beta peptide inhibits amyloid formation. Proc Natl Acad Sci USA 2008; 105: 5099-104.

[48] Smith TJ, Stains CI, Meyer SC, Ghosh I. Inhibition of beta-amyloid fibrillization by directed evolution of a beta-sheet presenting miniature protein. J Am Chem Soc 2006; 128: 14456-7.
[49] Funke SA, Willbold D. Mirror image phage display-a method to generate D-peptide ligands for use in diagnostic or therapeutical applications. Mol Biosyst 2009; 5: 783-6.

[50] van Groen T, Wiesehann K, Funke SA, Kadish I, Nagel-Steger L, Willbold D. Reduction of Alzheimer's disease amyloid plaque load in transgenic mice by D3, a D-enantiomeric peptide identified by mirror image phage display. ChemMedChem 2008; 3: 1848-52.

[51] Funke SA, van Groen T, Kadish I, et al. Oral treatment with the Denantiomeric peptide D3 improves the pathology and behavior of Alzheimer's disease transgenic mice. ACS Chem Neurosci 2010; 1 : 639-48.

[52] Liu HM, Funke SA, Willbold D. Transport of Alzheimer disease amyloid-beta-binding $\mathrm{D}$-amino acid peptides across an in vitro blood-brain barrier model. Rejuvenation Res 2010; 13: 210-13.

[53] Kawasaki T, Onodera K, Kamijo S. Selection of peptide inhibitors of soluble A beta (1-42) oligomer formation by phage display. Biosci Biotech Biochem 2010; 74: 2214-9.

[54] Orner BP, Liu L, Murphy RM, Kiessling LL. Phage display affords peptides that modulate beta-amyloid aggregation. J Am Chem Soc 2006; 128: 11882-9.

[55] Wurth C, Guimard NK, Hecht MH. Mutations that reduce aggregation of the Alzheimer's Abeta42 peptide: an unbiased search for the sequence determinants of Abeta amyloidogenesis. J Mol Biol 2002; 319: 1279-90.

[56] de Groot NS, Aviles FX, Vendrell J, Ventura S. Mutagenesis of the central hydrophobic cluster in A beta 42 Alzheimer's pepticle Side-chain properties correlate with aggregation propensities. FEBS J 2006; 273: 658-68.

[57] Kim W, Hecht MH. Mutations enhance the aggregation propensity of the Alzheimer's A beta peptide. J Mol Biol 2008; 377: 565-74.

[58] Kim W, Kim Y, Min J, Kim DJ, Chang YT, Hecht MH. A highthroughput screen for compounds that inhibit aggregation of the Alzheimer's peptide. ACS Chem Biol 2006; 1: 461-9.

[59] Fox A, Snollaerts T, Casanova CE, Calciano A, Nogaj LA, Moffet DA. Selection for nonamyloidogenic mutants of islet amyloid polypeptide (IAPP) identifies an extended region for amyloidogenicity. Biochemistry 2010; 49: 7783-9.

[60] Baine M, Georgie DS, Shiferraw EZ, Nguyen TPT, Nogaj LA, Moffet DA. Inhibition of A beta 42 aggregation using peptides selected from combinatorial libraries. J Pept Sci 2009; 15: 499-503.

[61] Apostolidou M, Jayasinghe SA, Langen R. Structure of alphahelical membrane-bound human islet amyloid polypeptide and its implications for membrane-mediated misfolding. J Biol Chem 2008; 283: 17205-10.

[62] Hull RL, Westermark GT, Westermark P, Kahn SE. Islet amyloid: a critical entity in the pathogenesis of type 2 diabetes. J Clin Endocrinol Metab 2004; 89: 3629-43

[63] Kahn SE, Andrikopoulos S, Verchere CB. Islet amyloid: A longrecognized but underappreciated pathological feature of type 2 diabetes. Diabetes 1999; 48: 241-53.

[64] Matveyenko AV, Butler PC. Islet amyloid polypeptide (IAPP) transgenic rodents as models for type 2 diabetes. ILAR J 2006; 47: 225-33.

[65] Cao P, Meng F, Abedini A, Raleigh DP. The ability of rodent islet amyloid polypeptide to inhibit amyloid formation by human islet amyloid polypeptide has important implications for the mechanism of amyloid formation and the design of inhibitors. Biochemistry 2010; 49: 872-81.

[66] Westermark P, Engstrom U, Johnson KH, Westermark GT, Betsholtz C. Islet amyloid polypeptide - pinpointing amino-acidresidues linked to amyloid fibril formation. Proc Natl Acad Sci USA 1990; 87: 5036-40.

[67] Nanga RP, Brender JR, Xu J, Veglia G, Ramamoorthy A. Structures of rat and human islet amyloid polypeptide IAPP(1-19) in micelles by NMR spectroscopy. Biochemistry 2008; 47: 12689-97.

[68] Abedini A, Raleigh DP. Destabilization of human IAPP amyloid fibrils by proline mutations outside of the putative amyloidogenic domain: Is there a critical amyloidogenic domain in human IAPP? J Mol Biol 2006; 355: 274-81.

[69] Marek P, Abedini A, Song BB et al. Aromatic interactions are not required for amyloid fibril formation by islet amyloid polypeptide but do influence the rate of fibril formation and fibril morphology. Biochemistry 2007; 46: 3255-61.

[70] Abedini A, Meng FL, Raleigh DP. A single-point mutation converts the highly amyloidogenic human islet amyloid polypeptide 
into a potent fibrillization inhibitor. J Am Chem Soc 2007; 129: 11300.

[71] Abedini A, Raleigh DP. The role of His-18 in amyloid formation by human islet amyloid polypeptide. Biochemistry 2005; 44 : 16284-91.

[72] Koo BW, Hebda JA, Miranker AD. Amide inequivalence in the fibrillar assembly of islet amyloid polypeptide. Protein Eng Des Select 2008; 21: 147-54.

[73] Scrocchi LA, Chen Y, Waschuk S et al. Design of peptide-based inhibitors of human islet amyloid polypeptide fibrillogenesis. J Mol Biol 2002; 318: 697-706.
[74] Tracz SM, Abedini A, Driscoll M, Raleigh DP. Role of aromatic interactions in amyloid formation by peptides derived from human Amylin. Biochemistry 2004; 43: 15901-8.

[75] Larson JL, Miranker AD. The mechanism of insulin action on islet amyloid polypeptide fiber formation. J Mol Biol 2004; 335: 22131 .

[76] Wiltzius JJW, Sievers SA, Sawaya MR, Eisenberg D. Atomic structures of IAPP (amylin) fusions suggest a mechanism for fibrillation and the role of insulin in the process. Protein Sci 2009; 18 : 1521-30.

(C) Neddenriep et al.; Licensee Bentham Open.

This is an open access article licensed under the terms of the Creative Commons Attribution Non-Commercial License (http://creativecommons.org/licenses/by-nc/3.0/) which permits unrestricted, non-commercial use, distribution and reproduction in any medium, provided the work is properly cited 